\title{
Interpersonal Needs and Functional Area of Management
}

\author{
RAYMOND E. HILL ${ }^{1}$ \\ University of Michigan
}

\begin{abstract}
This study examines a sample of first-semester MBA students to determine the relationship between their interpersonal needs and their preferences for a functional area of management. The students were categorized according to their preference for one of the following eight functional areas: accounting, systems analysis, finance, small business management, engineering, marketing, manufacturing management, and personnel management. Interpersonal needs were measured by the Fundamental Interpersonal Relations Orientation (FIRO-B) instrument developed by W. C. Schutz. Significant differences in interpersonal needs were found among students preferring different functional specialities. Implications of the results are discussed in terms of occupational choice processes.
\end{abstract}

This study examines differences in interpersonal needs of first-semester MBA students who prefer different functional areas of management. Even though selection of a functional specialty is only one of many sequential preferences an individual is likely to express over time in gravitating toward a business career, the findings were considered relevant to occupational choice and career development processes.

Roe (1956, 1969), Roe and Siegelman (1964), and Bordin, Nachmann, and Segal (1963) have theorized the central role that need gratification plays in occupational choice. They also suggest, in the Freudian tradition, that a need orientation is developed through childhood experiences and that this orientation reflects an element of constancy in the individual. Roe feels that parent-child relations and family atmosphere result in a major orientation either toward persons or away from persons and that this basic predisposition influences a whole series of choices over time with regard to interest development, occupation, and career development. Roe and Klos (1969) in an extension and slight revision of Roe's original work have presented a two-way classification scheme for occupations based on an interpersonal dimension and a level or responsibility dimension. On the interpersonal dimension, the occupations vary with respect to the intensity and nature of the person interactions involved in the occupational activities. The level dimension varies

1 Requests for reprints should be sent to Raymond E. Hill, Organizational Behavior, Graduate School of Business Administration, University of Michigan, Ann Arbor, Michigan 48104. 
with regard to amount of influence over other people. Bordin and his associates have developed a model which attempts to describe occupations in terms of their relation to ten types of need-gratifying activities. According to their theory, the individual seeks that occupational role which will be rewarding in terms of his particular needs.

There are several other conceptualizations of the occupational choice process; however, since the two cited above are most appropriate for the purposes of this study the others will not be pursued. Commenting on the work by Roe and Bordin, Super and Bohn (1970, p. 100) note:

It is one thing to hypothesize relationships between needs and occupations according to a logical schema and explanation. It is something else to obtain evidence in support of these basic hypotheses. While some formulations about needs and personality make good sense and have a certain amount of appeal, in general the data have not lived up to the expectations. No generalizations can be made; however, there is evidence for some relationships. . .

One of the early studies to test Roe's framework was conducted by Grigg (1959) using graduate nurses and female physics, chemistry, and mathematics majors. The results of the Grigg study did not support Roe's hypotheses regarding the impact of early family atmosphere on vocational choice. Hagen (1960) used independent judges to conduct an extensive study into the family backgrounds of Harvard graduates. He then attempted to relate the diagnosed family environment to occupational choice but met with only minimal success. Hagen $(1960$, p. 255$)$ concludes:

Except in the case of a casual family atmosphere, the posited relationships between the specific family climates and a later career choice are not supported in these data.

Similar negative findings were reported by Switzer, Grigg, Miller, and Young (1962) in an attempt to differentiate between ministerial students and chemistry majors using measures of early family atmosphere. Even Roe's own attempts at validating her framework were disappointing (Roe \& Siegelman, 1964). Crites (1969, p. 239), in summarizing the evidence on Roe's work, concludes that relationships between parental attitudes and occupational choices are certainly not gross, easily detected ones, and whatever associations are found will probably be of low to moderate strength.

With regard to interpersonal needs and occupational preferences, several authors have documented associations in students between certain personality characteristics and choice of specialty within an academic or professional curriculum. Wasserman, Yufit, and Pollack (1969) found choice of specialty among medical students to be related to an intimacy-isolation personality 
dimension. Grace (1970) studied the Guilford-Zimmerman Temperament profiles of freshman business students in a junior-college program and found that students preferring accounting were apt to be less friendly than students selecting data processing, management, and office practice. Management majors were higher on ascendance (the need to dominate other people) than all other groups of students. In his analysis of senior undergraduate business majors, Harris (1971) found that accounting students rated significantly higher in control-related variables than did marketing students. Minor differences were found between accounting students and students in finance, management, and insurance.

Thus, several studies have documented personality differences among students in various specialties of a given curriculum. Among undergraduate business students, accounting majors in particular have been noted as being less friendly but have rated higher on control-related dimensions than students in other selected majors. Management majors were found to be higher on ascendance than students in certain other functional specialities.

The personality variables studied in this paper are the needs which find expression in interpersonal settings. The manager's job has been characterized as overwhelmingly interpersonal. Sayles $(1964$, p. 38$)$ suggests that administration involves virtually constant contact with people, and managers whose personalities do not dispose them toward a high amount of interpersonal activity are likely to be frustrated and dissatisfied. Thus it seems appropriate to examine the interpersonal needs of potential managers (MBA students).

\section{METHODOLOGY}

Sample. The Fundamental Interpersonal Relations Orientation (FIRO-B) instrument developed by Schutz (1966) for measuring interpersonal needs was administered to 146 first-semester MBA students under supervised group conditions during the fall of 1971. The sample consisted of 11 females and 135 males, but they were not separated out.

Instrument. The FIRO questionnaire attempts to quantify three basic interpersonal needs-inclusion, control, and affection-which were hypothesized by Schutz in his three-dimensional theory of interpersonal behavior. The three areas are considered descriptive, in a general sense, of the fundamental behaviors that occur interpersonally. Inclusion refers to the need to be included in other people's activities, or to include others in one's own activities, and is analogous to the introversion-extraversion dimension of other authors or to sociability. It entails moving toward or away from people psychologically (Schutz, 1966, p. 21). Control refers to the need to give and receive structure, directions, influence, power, and authority and corresponds roughly to authoritarianism or the need for power used in other studies 
(Schutz, 1966, Chap. 5). Affection is concerned with emotional closeness to others, friendship, liking or disliking, and refers to the need to act in a personal way toward others or to receive friendly behavior from others. It is analogous to the need for affiliation (Schutz, 1966, p. 58).

Each of the three need areas is scaled from a low of 0 to a high of 18 . In addition, all three scales can be summed to obtain an estimate of the need for total interpersonal activity. This composite scale ranges from a low of 0 to a high of 54 .

Schutz's framework is based on Freud; he suggests that individuals develop a rather stable or fundamental profile of interpersonal needs from early childhood experiences. In Schutz's opinion this fundamental orientation results in a certain relational continuity or constancy over time with the result that an adult repeats the interpersonal behavior patterns he learned as a child.

Procedure. The students were asked to select the one area in which they would most prefer to work upon graduation from among a list of ten functional areas of management. The ten areas included finance, systems analysis, accounting, marketing, small business management, personnel management, manufacturing supervision, engineering, sales, and labor relations. If the list did not include the student's first preference, write-ins were allowed. The choice of functional area was written on the FIRO instrument and no student was required to disclose his name. Thus the preferences and test scores were completely anonymous. The FIRO instruments were scored and the scores were then categorized into particular areas of management.

Hypotheses. Although the literature does not indicate precisely what the nature of the differences in interpersonal needs might be for the different functional specialties, it was expected that those preferring accounting and systems analysis would rate lower on total activity needed than those opting for other areas because the two specialties are primarily concerned with data analysis and are thus oriented toward infrequent contact with people. Thus Hypothesis 1 reads:

$\mathrm{H}_{1}$ : Students preferring accounting and systems analysis will rate lower on total interpersonal activity needed than students preferring the other specialties.

The three individual need areas were expected to show differences similar to total activity, with the exception of the control dimension. It was expected that the accounting and systems analysis categories would be higher on the control scale since much of the work in these fields is oriented toward control activity even though it is not explicitly interpersonal. Individual tests of the above hypothetical relations for the separate need scales cannot be made, however, due to the structure of the data. The FIRO scales are highly intercorrelated as shown in Table 1 and a composite hypothesis of the above relations is therefore indicated. Thus Hypothesis 2 states: 
TABLE 1

\begin{tabular}{lccc}
\multicolumn{4}{c}{ Intercorrelation of FIRO Scales } \\
\hline & Inclusion & Control & Affection \\
\hline Inclusion & 1.00 & $.36^{*}$ & $.64^{*}$ \\
Control & & 1.00 & $.24^{*}$ \\
Affection & & & 1.00 \\
\hline
\end{tabular}

${ }^{*} p<.01$.

$\mathrm{H}_{2}$ : Students preferring accounting and systems analysis will rate lower on inclusion and affection, but higher on control than students preferring other specialties.

\section{RESULTS}

The first hypothesis was tested using a one-factor analysis of variance (ANOVA) on the total FIRO scores where the levels of the factor represented different functional areas. The second hypothesis was tested using a multivariate one-way analysis of variance (MANOVA) where the multiple variates were inclusion, control and affection. ${ }^{2}$ The assumptions of the MANOVA model are consistent with dependencies among the variates (Morrison, 1967, p. 168). The levels of the factor were again the functional areas. The MANOVA procedure tests whether there are differences between the mean vectors for the three variates by factor level. The null hypothesis is that the mean vectors are equal across levels of the factor. The assumption of homogeneous variances and covariances was supported for both the ANOVA and MANOVA procedures. The final calculations were performed on eight functional areas and 138 subjects. Two areas, sales and labor relations, were dropped since each was chosen by only four respondents. The ANOVA and MANOVA results are explained below.

Total interpersonal activity versus functional area. Figure 1 shows means and standard deviations of total activity by functional area. Sample sizes $(\mathrm{N})$ are also shown for each area. Table 2 presents the ANOVA results for the data illustrated in Fig. 1.

The analysis of variance indicated that the observed differences in the mean total interpersonal activity levels across functional areas were statistically significant at the .03 level.

${ }^{2}$ This analysis was conducted using the MANOVA program at The University of Michigan's Computing Center. It tests the assumption of equal covariance matrices and prints out an $F$ statistic approximation to the Wilkes $\Lambda$ criterion for rejecting the null hypothesis. 


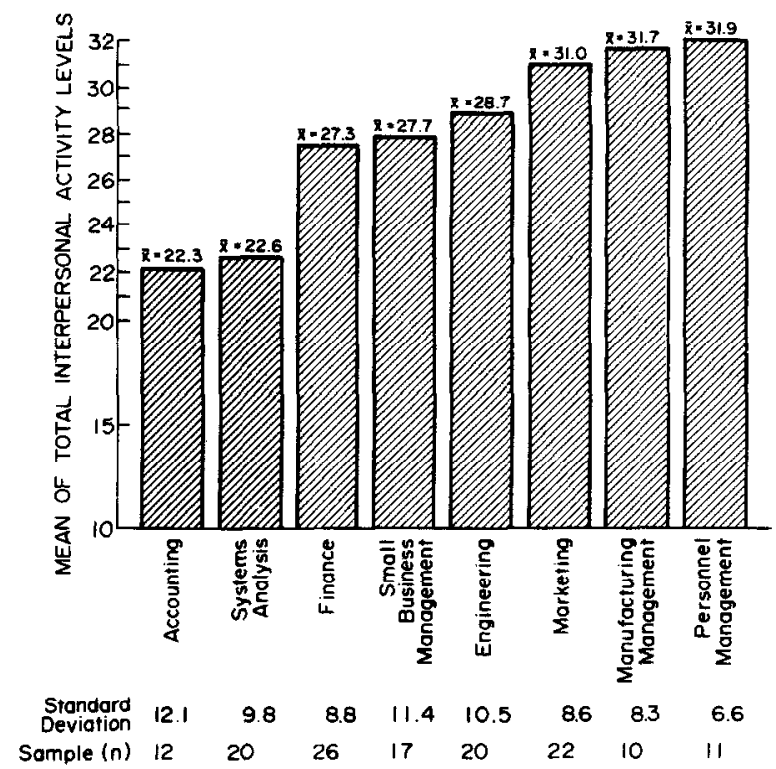

Fig. 1. Means and standard deviations for total interpersonal activity level by functional area.

TABLE 2

Analysis of Variance for Total Interpersonal Activity Level by Functional Area ${ }^{a}$

\begin{tabular}{lccc}
\hline \multicolumn{1}{c}{ Source } & Sum of squares & Degrees of freedom & Mean square \\
\hline Between strata (areas) & $1,490.0$ & 7 & 212.86 \\
Within strata (areas) & $\underline{12,113.0}$ & $\underline{130}$ & 93.17 \\
& $13,603.0$ & 137 & \\
\hline
\end{tabular}

$a_{F}$ statistic $=2.28, p \leqslant .03$.

It is interesting to note that the accounting and systems analysis areas rate lowest in interpersonal activity levels. The eight areas cluster into three groups of approximately equal means: Group 1 is composed of accounting and systems analysis; Group 2 of finance, small business management, and engineering; and Group 3 of marketing, manufacturing supervision, and personnel management. The use of pairwise $t$-statistics for comparing two individual functional areas indicated that each of the areas of Group 1 was significantly different from each area of Group 3 beyond the .05 level. No 
TABLE 3

Multivariate One-Way Analysis of Variance on the Means for Inclusion, Control and Affection by Functional Areas ${ }^{a}$

\begin{tabular}{lcccccccr}
\hline & $\begin{array}{c}\text { Account- Systems } \\
\text { ing }\end{array}$ & analysis & Finance & $\begin{array}{c}\text { Susiness } \\
\text { mgt. }\end{array}$ & $\begin{array}{c}\text { Engi- } \\
\text { neering }\end{array}$ & $\begin{array}{c}\text { Market- } \\
\text { ing }\end{array}$ & $\begin{array}{c}\text { Manu- } \\
\text { factur- } \\
\text { ing mgt. }\end{array}$ & $\begin{array}{c}\text { Person- } \\
\text { nel mgt. }\end{array}$ \\
\hline Inclusion & 7.8 & 7.6 & 9.7 & 9.5 & 9.5 & 11.2 & 11.2 & 12.5 \\
Control & 8.6 & 8.3 & 9.2 & 8.7 & 10.0 & 9.6 & 11.8 & 9.5 \\
Affection & 5.9 & 6.7 & 8.4 & 9.6 & 9.6 & 10.3 & 10.1 & 10.0 \\
\hline
\end{tabular}

$a_{\mathrm{df}}=21,368, F=1.6, p<.05$

Group 2 area was significantly different from any area of Group 3. The systems mean (Group 1) was significantly different from the engineering mean (Group 2), however.

It appears in general that persons preferring accounting and systems analysis have a significantly lower need as a group for interpersonal activity than persons preferring marketing, manufacturing, or personnel.

The mean vectors versus functional area. Table 3 shows the MANOVA analysis which includes the means for inclusion, control and affection by functional area, the degrees of freedom and the approximated $F$ statistic. The sample sizes are the same as those shown in Fig. 1. This analysis indicated that the observed differences in the mean vectors across functional areas were statistically significant at the .05 level.

As indicated by Table 3, the accounting and systems analysis areas are lowest on the inclusion and affection scales whereas marketing, manufacturing management and personnel management are highest on inclusion and affection. Pairwise comparisons of the various levels indicated that systems analysis was significantly different than marketing, manufacturing, and personnel at the .05 level, and that accounting was significantly different than marketing and manufacturing at the .05 level.

The control dimension did not follow the expected directional pattern and was in fact the reverse. Accounting and systems analysis tended to be low on control whereas manufacturing, engineering and marketing were among the highest.

Inspection of Table 3 suggests that all three scales follow the same general trend as the total activity levels. The inclusion and affection means, however, tend to manifest the largest differences, with ranges of 4.9 and 4.4 , respectively. The range of the control means is 3.5 (difference between highest and lowest mean). 


\section{DISCUSSION}

The first general pattern which emerges from the data is that preference for functional areas is related to the need for total interpersonal activity. In general, the functional areas divide into three groups at different levels on the total activity scale: accounting and systems analysis are the lowest; finance, small business, and engineering are in the middle; and marketing, manufacturing, and personnel are highest.

It appears that all three dimensions of interpersonal life add to the pattern of differences of total activity; inclusion and affection show larger differences than control, but it should be noted that their differential impacts were not evaluated statistically. Both analyses of variance suggest, however, that subjects opting for accounting and systems analysis prefer less active, arm's length interpersonal relations than do subjects opting for marketing, manufacturing or personnel. The latter three specialities appear to have strong needs for a more vigorous and friendly interpersonal life. Subjects who preferred finance, engineering, or small business management were generally intermediate with respect to interpersonal needs. Thus Hypothesis 1 was supported, but Hypothesis 2 was only partially supported because control needs exhibited the opposite of the hypothesized relation.

The association between interpersonal needs and preference for a functional area of management suggests that perhaps the general predictor variable in Roe's framework (orientation toward or away from people) is useful in the context of business oriented occupations. These results are interesting since previous research has not particularly demonstrated the usefulness of this variable as a predictor of Roe's occupational classes.

One of the differences between the present study and previous tests of Roe's work is that the occupational classes used here were very narrow, compared to the broad classes defined by Roe. Perhaps these findings corroborate Hagen's $(1960$, p. 255$)$ explanation of his negative results when he concludes:

....we are inclined to think failure occurred because sufficient differentiations among careers is not represented in Roe's theory.

A second factor which perhaps led to strong associations in this study was the use of a standardized, validated instrument to measure interpersonal needs. The FIRO instrument has been fairly extensively studied and is an explicit attempt to measure an interpersonal orientation which is acknowledged to arise from early childhood. Crites $(1969$, p. 236$)$ suggests that several tests of Roe's theory used unvalidated or unstandardized instruments.

A third aspect of the present data should also be pointed out. Roe's hypotheses tend to be oriented toward male subjects (Crites, p. 236), and 
some of the early negative findings used female subjects (Grigg, 1959 and Utton, 1962). The sample in this study was 93 per cent male and represents a sample appropriate to Roe's theory.

The present data indicate a link between specific needs and a particular preference in the occupational choice process. Admittedly, use of need data to predict future occupational roles does not necessarily follow, since there are many intervening variables which obscure the connection between needs and ultimate choice of occupation. An individual makes many choices over time, and it is difficult to determine which job represents his ultimate occupational role. Walsh (1959) has also found that people actively restructure their jobs to meet their own needs, again decreasing the effectiveness of need data in predicting categorical occupational choices. In any event, the present data establish a differential association between interpersonal needs and occupational preference, and as such raise the question as to the influence of childhood forces on career processes.

\section{REFERENCES}

Bordin, E. S.; Nachmann, B.; and Segal, S. J. An articulated framework for vocational development. Journal of Counseling Psychology, 1963, 10, 107-117.

Crites, J. Vocational psychology. New York: MoGraw-Hill, 1969.

Grace, E. The relationship between personality traits and vocational interests in the choice of field of study of selected junior college students in business administration. Dissertation Abstracts International, May 1970, 30, 4827.

Grigg, A. Childhood experiences with parental attitudes: A test of Roe's hypothesis. Journal of Counseling Psychology, 1959, 6, 153-156.

Hagen, D. Careers and family atmosphere: A test of Roe's Theory, Journal of Counseling Psychology, 1960, 7, 251-256.

Harrell, T. Managers' performance and personality. Cincinnati: South-Western, 1961.

Harris, S. B. A comparison of the personality traits of accounting students, students in selected majors, and successful accountants. Dissertation Abstracts International, $1971,31,4324-4325$.

Huttner, L.; Levy, S.; Rosen, E.; and Stopol, M. Further light on the executive personality. Personnel, 1959, 36, 42-50.

Morrison, D. F. Multivariate statistical methods. New York, McGraw-Hill, 1967.

Roe, A. The psychology of occupations. New York: Wiley, 1956.

Roe, A., and Siegelman, M. The origin of interests. Inquiry study No. 1, American Personnel Guidance Association, 1964.

Roe, A. Occupational classification. Proceedings of the 77th Annual Convention of the American Psychological Association, 1969, 4 (Part 2), 695-696.

Roe, A., and Klos, D. Occupational classification. Counseling Psychologist, 1969, 1(3), 84-88.

Sayles, L. Managerial behavior. New York: MoGraw-Hill, 1964.

Schutz, W. The interpersonal underworld. Palo Alto: Science and Behavior Books, Inc., 1966.

Super, D. and Bohn, M., Jr. Occupational psychology. Belmont, Calif.: Wadsworth Publishing Co., 1970. 
Switzer, D.; Grigg, A.; Miller, J.; and Young, R. Early experiences and occupational choices: A test of Roe's hypothesis. Journal of Counseling Psychology, 1962, 9, $45-48$.

Utton, A. Recalled parent-child relations as determinants of vocational choice. Journal of Counseling Psychology, 1962, 9, 49-53.

Walsh, R. The effects of needs on responses to job duties. Journal of Counseling Psychology, 1959, 6, 194-198.

Wasserman, E.; Yufit, R.; and Pollack, G. Medical specialty choice and personality: II. Outcome and postgraduate follow-up results. Archives of General Psychiatry, 1969, 21, 529-535.

Received: September 25, 1972. 